\title{
Rancang Bangun Sistem Pendukung Keputusan Penyeleksian Peserta Paskibraka Dengan Menggunakan Metode Analitycal Hierarchy Procces (AHP) (Study Kasus : Dinas Pendidikan Pemuda Dan Olahraga Provinsi Sumatera Barat)
}

\author{
Nia Febriyani \\ Dosen Teknologi Informatika STMIK-AMIK RIAU \\ febriyaninia@gmail.com
}

\begin{abstract}
ABSTRAK
Setiap tahun, Dinas Pemuda dan Olahraga akan menyeleksi Pasukan Pengibar Bendera Pusaka (PASKIBRAKA) untuk memperingati hari ulang tahun kemerdekaan Republik Indonesia. Siswa-siswi dari beberapa sekolah seProvinsi Sumatera Barat akan dipanggil mewakili sekolah masing-masing untuk mengikuti seleksi anggota Paskibraka. AHP dalam sistem pendukung keputusan ini menghasilkan sebuah aplikasi sistem pendukung keputusan penyeleksian yang bisa digunakan pada Instansi Pemerintahan. Hasil penelitian ini adalah menghasilkan urutan rangking dari calon peserta yang diseleksi dan output dari aplikasi tersebut dapat membantu pengambilan keputusan (decision maker) dalam menentukan peserta yang memenuhi semua kriteria yang ada. Aplikasi pada penelitian ini diimplementasikan dengan menggunakan bahasa pemrograman Visual Basic dan database menggunakan Mysql
\end{abstract}

Kata kunci: Sistem Pendukung Keputusan, AHP, Mysql

PENDAHULUAN

\subsection{Latar Belakang Masalah}

Dewasa ini, adanya Sistem Pendukung Keputusan (SPK) di suatu organisasi dapat dipandang sebagai aset penting untuk menunjang kelancaran aktifitas dan tercapainya tujuan strategis organisasi. SPK dapat hadir dalam berbagai bentuk, mulai dari bentuk sederhana berupa pengolahan data menggunakan spreadsheet hingga bentuk aplikasi yang kompleks dan terintegrasi, dapat dimanfaatkan untuk mempercepat dan meningkatkan kualitas proses pembuatan keputusan di suatu organisasi. Penggunaan SPK tidak terbatas pada tingkat manajerial, tetapi dapat meluas mulai dari tingkat strategis hingga 
operasional, tergantung dari ruang lingkup dan jenis informasi yang diolah.

Salah satu karakteristik keputusan yang dapat didukung oleh SPK antara lain yaitu keputusan tersebut bersifat terstruktur atau semi terstruktur. Terstruktur dalam artian untuk memperoleh satu keputusan, terdapat serangkaian prosedur yang harus diikuti dan kriteria untuk masing - masing prosedur bersifat jelas dan kuantitatif, kadang kadang pihak pembuat keputusan berhak memasukkan pertimbangan - pertimbangan tertentu yang bersifat subyektif, tetapi tetap berdasarkan alasan yang diturunkan dari data - data kuantitatif. Dalam bidang pengelolaan SDM misalnya, proses seleksi dapat dibuat terstruktur , tetapi ketika sampai pada keputusan akhir, ada kemungkinan keputusan tesebut diambil dengan didasari oleh pertimbangan tertentu, selain data kuantitatif.

Salah satu proses pengelolaan SDM yang berpeluang untuk dibantu oleh SPK adalah proses seleksi. Biasanya proses seleksi yang sudah distandarisasi dengan baik akan terdiri atas serangkaian prosedur dimana para calon peserta harus melewati sekian lapis tahapan dan memennuhi kriteria tertentu. Pada akhir seleksi, pihak penentu keputusan berhak memutuskan untuk menerima atau menolak calon peserta berdasarkan pertimbangan hasil seleksi secara kuantitatif maupun kualitatif dan subyektif.
Pada penelitian ini, akan dicoba merancang sebuah sistem pendukung keputusan untuk membantu proses seleksi peserta paskibraka tingkat Nasional di Dinas Pendidikan Pemuda dan Olahraga Provinsi Sumatera Barat yang sudah memiliki serangkaian prosedur seleksi yang terstruktur dan jelas., tetapi belum didukung oleh serangkaian sistem informasi yang memadai.

Hasil yang diharapkan dari rancangan sistem ini adalah didapatkannya sebuah model SPK untuk seleksi calon paskibraka yang mampu menyediakan data dengan cepat, transparan dan membantu proses seleksi itu sendiri. Selain itu, sistem juga diharapkan menjadi semacam 'bank data' profil sumber daya manusia khususnya calon peserta dasar yang akan sangat membantu proses seleksi berikutnya.

\subsection{Perumusan Masalah}

Berdasarkan keterangan yang diperoleh mengenai pengolahan data seleksi peserta Paskibraka maka dapat dirumuskan beberapa permasalahan :

1. Seperti apakah sistem pengambilan keputusan terhadap seleksi peserta Paskibraka tingkat nasional yang sedang berjalan?

2. Bagaimana mengoptimalkan proses pengambilan keputusan untuk seleksi peserta Paskibraka tingkat nasional yang sedang berjalan agar informasi 
yang dihasilkan cepat, tepat, dan berkualitas?

3. Apakah pembuatan sistem baru dengan menambahkan sistem penunjang keputusan dapat berpengaruh terhadap Dinas Pendidikan Pemuda dan Olahraga dalam pemilihan peserta Paskibraka?

\subsection{Batasan Masalah}

Untuk lebih mengarahkan penulisan ini pada tujuan yang diinginkan seperti yang telah diuraikan diatas, maka perlu batasan masalah agar tidak menyimpang dari tujuan semula, yang mana penulis lebih memfokuskan untuk seleksi peserta Paskibraka tingkat nasional saja dan tidak membahas tingkatan - tingkatan sekolah lainnya.

\subsection{Hipotesa}

hipotesa sebagai jawaban sementara dari permasalahan ini yaitu:

1. Diduga pengambilan keputusan untuk seleksi peserta Paskibraka tingkat nasional di Dinas Pemuda Pendidikan dan Olahraga Provinsi Sumatera Barat ini masih dilakukan secara manual.

2. Dengan adanya Sistem Pendukung Keputusan (SPK) untuk seleksi peserta Paskibraka tingkat nasional ini,

Dinas Pendidikan Pemuda dan Olahraga Provinsi Sumatera Barat mampu mengoptimalkan proses pengambilan keputusan sehingga keputusan yang dihasilkan nantinya dalam tepat, dalam waktu yang cepat dan berkualitas.

3. Dengan adanya sebuah program aplikasi Sistem Pendukung Keputusan untuk seleksi peserta Paskibraka tingkat nasional dengan bahasa pemrograman Visual Basic 6.0 dapat meningkatkan kinerja Dinas Pendidikan Pemuda dan Olahraga Provinsi Sumatera Barat khususnya untuk proses pengambilan keputusan.

\subsection{Tujuan Penelitian}

Adapun tujuan dari penelitian ini adalah sebagai berikut :

1. Untuk membantu Dinas Pendidikan Pemuda dan Olahraga Provinsi Sumatera Barat dalam seleksi peserta Paskibraka tingkat nasional dengan mengembangkan suatu aplikasi sistem pendukung keputusan.

2. Menganalisa sistem yang lama, agar diketahui kelemahan - kelemahan yang ada pada sistem tersebut khususnya dalam hal pengambilan keputusan dalam seleksi peserta Paskibraka tingkat nasional yang akan menjadi dasar perancangan sistem yang baru.

3. Membantu Dinas Pendidikan Pemuda dan Olahraga Provinsi Sumatera Barat 
untuk menghasilkan keputusan yang bekualitas, cepat dan transparan.

\subsection{Metode Penelitian}

Dalam melakukan penelitian ini, metode yang digunakan dalam mengumpulkan data adalah :

1. Penelitian Lapangan (Field research)

Penelitian yang dilakukan untuk mendapatkan data primer di Dinas Pendidikan Pemuda dan Olahraga Provinsi Sumatera Barat, dengan teknik observasi dan wawancara.

2. Penelitian Perpustakaan (Library research)

Penelitian yang dilakukan untuk memperoleh data sekunder, melalui literatur-literatur yang berhubungan dengan tema skripsi, untuk mencari informasi, menyusun teori-teori yang berhubungan dengan pembahasan sehingga terjadi perpaduan yang komplek yang satu dengan yang lainnya.

3. Penelitian laboratorium ( Laboratory research)

Penelitian yang dilakukan dengan menggunakan hardware dan software.

\section{LANDASAN TEORI}

\subsection{Konsep Dasar Sistem Pendukung} Keputusan

Konsep sistem pendukung keputusan pertama kali diperkenalkan oleh Michael S. Scott pada awal tahun 1970-an dengan menggunakan istilah Management Decision System.

Sistem Pendukung Keputusan (SPK) adalah sebuah sistem yang dimaksudkan untuk mendukung para pengambil keputusan manajerial dalam situasi keputusan semi terstruktur. sistem pendukung keputusan dimaksudkan untuk menjadi alat bantu bagi para pengambil keputusan untuk memperluas kapabilitas mereka, namun tidak untuk menggantikan penilaian mereka. Sistem pendukung keputusan ditujukan untuk keputusan-keputusan yang memerlukan penilaian atau pada keputusan-keputusan yang sama sekali tidak dapat didukung oleh algoritma.

\subsection{Metode Analitycal Hirarchy Process (AHP)}

Langkah-langkah yang dilakukan dalam metode AHP sebagai berikut :

1. Mendefinisikan masalah dan menetukan solusi yang diinginkan, lalu menyusun hierarki dari permasalahan yang dihadapi. Penyusunan hierarki adalah dengan menetapkan tujuan yang merupakan sasaran sistem secara keseluruhan pada level terbatas.

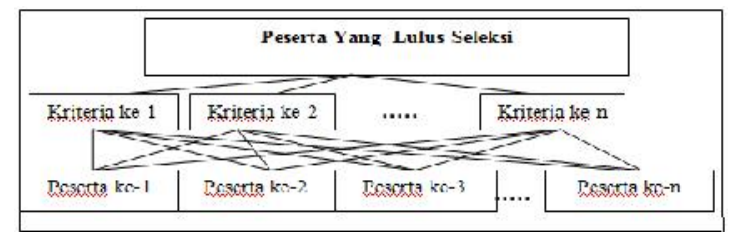

Gambar 2.1. Struktur Hirarki AHP 


\section{Menentukan Prioritas Elemen}

a. Langkah pertama dalam menentukan prioritas elemen adalah membuat perbandingan pasangan, yaitu membandingkan elemen secara berpasangan sesuai kriteria yang diberikan.

b. Matriks perbandingan berpasangan diisi menggunakan bilangan untuk merepresentasikan kepentingan relatif dari suatu elemen terhadap elemen yang lainnya.

Tabel 2.1. Skala Perbandingan

Berpasangan

\begin{tabular}{|c|l|}
\hline $\begin{array}{l}\text { Itensitas } \\
\text { kepentingan }\end{array}$ & Keterangan \\
\hline 1 & Elemen kedua sama pentingnya \\
\hline 3 & $\begin{array}{l}\text { Elemen yang satu sedikit lebih } \\
\text { penting daripad elemen yang } \\
\text { lainnya }\end{array}$ \\
\hline 5 & $\begin{array}{l}\text { Elemen yang satu lebih penting } \\
\text { daripada elemen yang lainya }\end{array}$ \\
\hline 7 & $\begin{array}{l}\text { Satu elemen jelas lebih mutlak } \\
\text { penting daripada elemen lainnya }\end{array}$ \\
\hline 9 & $\begin{array}{l}\text { Satu elemen mutlak penting } \\
\text { daripada elemen lainny }\end{array}$ \\
\hline $2,4,6,8$ & $\begin{array}{l}\text { Nilai - nilai antara dua nilai } \\
\text { pertimbangan yang berdekatan }\end{array}$ \\
\hline
\end{tabular}

\section{Sintesis}

Pertimbangan-pertimbangan terhadap perbandingan berpasangan disintesis untuk memperoleh keseluruhan prioritas. Hal-hal yang dilakukan dalam langkah ini adalah :

a. Menjumlahkan nilai-nilai dari setiap kolom pada matriks.

b. Membagi setiap nilai dari kolom dengan total kolom yang bersangkutan untuk memperoleh normalisasi matriks.

c. Menjumlahkan nilai-nilai dari setiap baris dan membaginya dengan jumlah elemen untuk mendapatkan nilai ratarata.

\section{Mengukur Konsistensi}

Dalam pembuatan keputusan, penting untuk mengetahui seberapa baik konsistensi yang ada, karena kita tidak menginginkan keputusan berdasarkan pertimbangan dengan konsisten yang rendah. Hal-hal yang dilakukan dalam langkah ini adalah :

a. Kalikan setiap nilai pada kolom pertama dengan prioritas relatif elemen pertama, nilai pada kolom kedua dengan prioritas relatif elemen kedua, dan seterusnya.

b. Jumlahkan setiap baris.

c. Hasil dari penjumlahan baris dibagi dengan elemen prioritas relatif yang bersangkutan.

d. Jumlahkan hasil bagi di atas dengan banyaknya elemen yang ada, hasilnya disebut $\lambda$ maks.

5. Hitung Consistency Index (CI), dengan rumus :

$$
C I=(\lambda \text { maks }-n) / n
$$


Dimana $\mathrm{n}=$ banyaknya elemen

6. Hitung Rasio Konsistensi/ Consistency Ratio $(C R)$ dengan rumus :

$$
C R=C I / I R
$$

dimana $: C R=$ Consistency Ratio

$$
C I=\text { Consistency Index }
$$$$
I R=\text { Indeks Random Consistency }
$$

7. Memeriksa Konsistensi Hirarki. Jika nilainya lebih dari $10 \%$, maka penilaian data judgment harus diperbaiki. Namun jika rasio konsistensi (CI/CR) kurang atau sama dengan 0,1 , maka hasil perhitungan bisa dinyatakan benar. Daftar Index Random Consistention (IR)

\section{Tabel 2.2. Daftar IR}

\begin{tabular}{|c|c|}
\hline Ukuran Matriks & Nilai IR \\
\hline 1,2 & 0.00 \\
\hline 3 & 0.58 \\
\hline 4 & 0.90 \\
\hline 5 & 1.12 \\
\hline 6 & 1.24 \\
\hline 7 & 1.32 \\
\hline$\ldots$ & $\ldots$ \\
\hline
\end{tabular}

\subsection{Kriteria Seleksi Calon Anggota Paskibraka}

Dalam penelitian ini diambil 4 kriteria yang akan dinilai, yaitu :
a. Kemahiran baris-berbaris (BB)
b. Nilai Pengetahuan Umum (PU)
c. Bahasa Inggris (BI)
d.Keterampilan Seni (Seni)

\section{PEMBAHASAN}

\subsection{Analisa Sistem}

Analisa sistem merupakan penguraian dari suatu system yang utuh kedalam bagianbagian komponennya sengan maksud mengidentifikasi dan mengevaluasi kekurangan, permasalahan dan hambatan yang terjadi dan kebutuhan yang diharapkan sehingga dapat diusulkan perbaikanperbaikan atau mengganti dengan sistem yang baru.

\subsection{Rancangan Proses AHP}

Langkah-langkah yang harus dilakukan untuk menentukan peserta yang lulus dengan menggunkan metode AHP adalah :

1. Menghitung Prioritas Kriteria

Menghitung nilai prioritas ini dilakukan untuk semua kriteria yang telah ditentukan sebelumnya.

a. Membuat Matriks Perbandingan Berpasangan

Tabel 3.1. Matrik Perbandingan

\section{Berpasangan}

\begin{tabular}{|c|c|c|c|c|}
\hline & BB & PU & BI & Seni \\
\hline BB & 1 & 2 & 2 & 3 \\
\hline PU & 0.50 & 1 & 2 & 2 \\
\hline BI & 0.50 & 0.50 & 1 & 2 \\
\hline Seni & 0.33 & 0.50 & 0.50 & 1 \\
\hline Jumlah & 2.33 & 4.00 & 5.50 & 8.00 \\
\hline
\end{tabular}


Penelitian Bidang Komputer Sains dan Pendidikan Informatika

b. Membuat Matrik Nilai Kriteria

Matriks ini diperoleh dengan menggunakan rumus :

Nilai baris kolom baru $=$ Nilai baris kolom lama / jumlah masing-masing kolom lama

Maka akan didapat nilai baru untuk setiap kolom, selanjutnya tiap baris dijumlahkan,Untuk nilai prioritas untuk setiap kriteria didapat dari jumlah masingmasing kolom dibagi dengan jumlah kriteria yaitu 4 kriteria

Tabel 3.2. Matriks Nilai Kriteria

\begin{tabular}{|l|l|l|l|l|l|l|}
\hline & BB & PU & BI & Seni & Jml & Prio \\
\hline BB & 0.43 & 0.50 & 0.37 & 0.37 & 1.67 & 0.41 \\
\hline PU & 0.21 & 0.25 & 0.36 & 0.25 & 1.07 & 0.26 \\
\hline BI & 0.21 & 0.13 & 0.18 & 0.25 & 0.77 & 0.19 \\
\hline Seni & 0.14 & 0.13 & 0.09 & 0.12 & 0.48 & 0.12 \\
\hline
\end{tabular}

c. Membuat Matriks Penjumlahan Setiap Baris

Matriks ini dibuat dengan mengalikan nilai prioritas yang didapat sebelumnya dengan matriks perbandingan berpasangan awal.

Tabel 3.3. Matriks Jumlah Baris

\begin{tabular}{|l|l|l|l|l|l|}
\hline & BB & PU & BI & Seni & Jml \\
\hline BB & 0.41 & 0.52 & 0.38 & 0.36 & 1.67 \\
\hline PU & 0.20 & 0.26 & 0.38 & 0.24 & 1.08 \\
\hline BI & 0.20 & 0.13 & 0.19 & 0.24 & 0.76 \\
\hline Seni & 0.14 & 0.13 & 0.09 & 0.12 & 0.48 \\
\hline
\end{tabular}

d. Penghitungan Rasio Konsistensi Penghitungan ini digunakan untuk memastikan bahwa rasio konsistensi $(\mathrm{CR}) \leq$ 0.1, jika ternyata nilai CR lebih besar dari 0.1 , maka matriks perbandingan berbasangan harus diperbaiki.

Tabel 3.4. Rasio Perhitungan Konsistensi

\begin{tabular}{|l|c|c|c|}
\hline & Jml/baris & Prio & Hasil \\
\hline BB & 1.67 & 0.41 & 2.08 \\
\hline PU & 1.08 & 0.26 & 1.34 \\
\hline BI & 0.76 & 0.19 & 0.95 \\
\hline Seni & 0.48 & 0.12 & 0.60 \\
\hline \multicolumn{3}{|c|}{ Jumlah } & 4.97 \\
\hline
\end{tabular}

Diketahui : Jumlah : 4.97

n(jumlah kriteria) : 4

$\lambda$ maks (jumlah/4) : $4.97 / 4=1.24$

$\mathrm{CI}((\lambda$ maks-n $) / \mathrm{n}):(1.24-4) / 4=-2.76 / 4=$ 0.69

$\mathrm{CR}(\mathrm{CI} / \mathrm{IR}$ (lihat table $):-0.69 / 0.9=-0.76$

Oleh karena $\mathrm{CR} \leq 0.1$, maka rasio konsistensi dari perhitungan tersebut bias diterima.

\section{Menghitung Prioritas Subkriteria}

Dalam menghitung prioritas subkriteria mengunakan rasio nilai : baik, cukup dan kurang dan dihitung untuk masing-masing kriteria. Yang mana untuk menghitung subkriteria untuk 1 kriteria langkahlangkahnya sama dengan langkah menghitung prioritas kriteria. 


\section{Menghitung Hasil}

Setelah nilai kriteria dan nilai subkriteria dihitung maka dapat disajikan matriks sebagai berikut :

Tabel 3.5. Matriks Hasil

\begin{tabular}{|c|c|c|c|}
\hline BB & PU & BI & Seni \\
\hline 0.41 & 0.26 & 0.19 & 0.12 \\
\hline Baik & Baik & Baik & Baik \\
\hline 1 & 1 & 1 & 1 \\
\hline Cukup & Cukup & Cukup & Cukup \\
\hline 0.46 & 0.56 & 0.41 & 0.33 \\
\hline Kurang & Kurang & Kurang & Kurang \\
\hline 0.21 & 0.30 & 0.17 & 0.10 \\
\hline
\end{tabular}

Selanjutnya memasukan data nilai dari semua peserta yang akan dihitung.

Contoh :

Tabel 3.6. Nilai Peserta

\begin{tabular}{|c|l|l|l|l|}
\hline Nis & \multicolumn{1}{|c|}{ BB } & PU & BI & Seni \\
\hline 001 & Baik & baik & Baik & Baik \\
\hline 002 & Cukup & baik & Baik & Baik \\
\hline 003 & Kurang & cukup & Cukup & baik \\
\hline
\end{tabular}

Dari hasil perhitungan data peserta, di dapat nilai total masing-masing peserta yang akan digunakan sebagai dasar untuk mendapatkan laporan siswa yang akan direkomendasikan sebagai peserta yang lulus seleksi atau rekomendasi dari sekolah masing-masing. Maka didapat hasil sebagai berikut :
Tabel 3.7. Hasil Akhir

\begin{tabular}{|c|c|c|c|c|c|}
\hline Nis & BB & PU & Bi & Seni & Total \\
\hline 001 & 0.42 & 0.27 & 0.19 & 0.12 & 1 \\
\hline 002 & 0.19 & 0.27 & 0.19 & 0.12 & 0.77 \\
\hline 003 & 0.09 & 0.15 & 0.08 & 0.12 & 0.44 \\
\hline
\end{tabular}

Nilai 0,42 pada kolom baris-berbaris baris 001 diperoleh dari nilai siswa untuk barisberbaris, yaitu baik dengan prioritas 1, dikalikan dengan prioritas baris-berbaris sebesar 0,42 .

Kolom total diperoleh dari penjumlahan pada masing-masing barisnya. Nilai total inilah yang dipakai sebagai dasar untuk merangking prestasi masing-masing peserta. Semakin besar nilainya, maka siswa tersebut semakin berpeluang untuk lulus seleksi menjadi peserta Paskibraka tingkat nasional dan akan ditugaskan ke Pusat. Dimana yang akan dikirim nantinya adalah 1 orang laki-laki dengan nilai tertinggi dan perempuan dengan nilai yang tertinggi.

\subsection{Rancangan Aplikasi Visual Basic}

Untuk mengimplementasikan program aplikasi yang telah dirancang, maka diperlukan sebuah alat bantu berupa komputer, yang mana untuk mengoperasikan komputer memerlukan tiga buah komponen pendukung seperti hardware, software, dan brainware.

\section{Menu Utama}

Menu utama adalah antar muka (interface) yang digunakan sebagai form induk / form utama. Form utama ini akan 
selalu ditampilkan saat program dijalankan

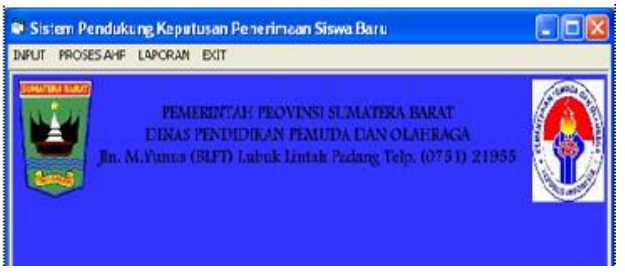

\section{Gambar 3.1. Form Menu Utama}

Menu utama terdiri dari tiga bagian menu yaitu :

1. Menu Input Data

Menu input data terdiri dari tiga sub menu yaitu :

a. Sub menu input data calon peserta Menampilkan form input data calon peserta dimana data-data tersebut akan di input dan disimpan di database program.

b. Sub menu input data nilai calon peserta

Menampilkan form input data nilai calon peserta dimana data-data nilai akan di input dan disimpan di database program.

c. Sub menu penilaian

Menampilkan form penilaian dimana data-data nilai calon peserta akan di input dan disimpan di database program.

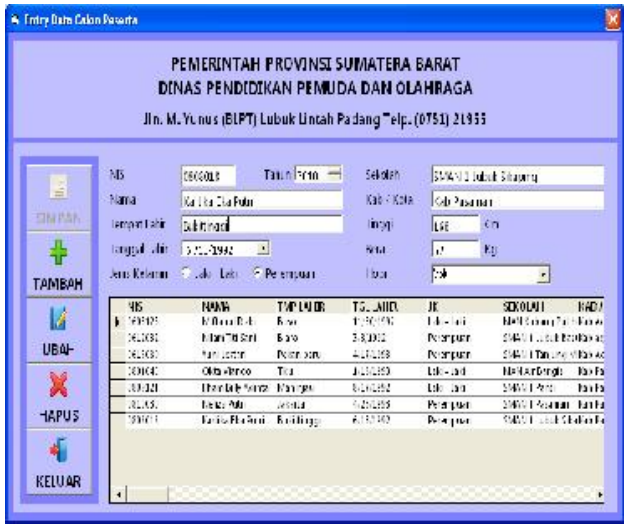

Gambar 3.1. Form Input Peserta

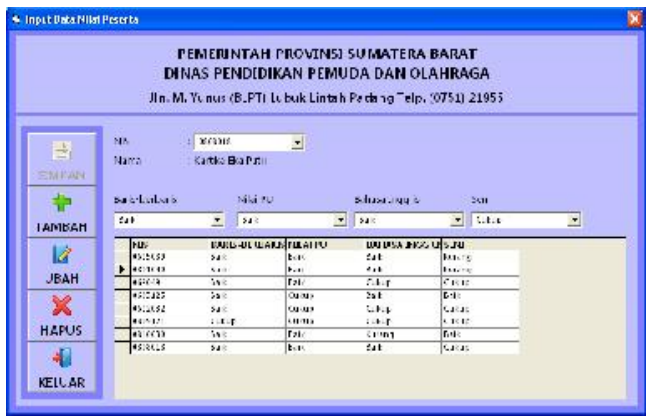

Gambar 3.2. Form Input Nilai Peserta

2. Menu Proses AHP

Menu proses AHP terdiri dari dua sub menu yaitu :

a. Sub menu menentukan prioritas kriteria

Menampilkan form-form untuk mencari nilai prioritas kriteria dengan menggunakan proses AHP.

b. Sub menu menetukan subprioritas subkriteria

Menampilkan form-form untuk mencari nilai subprioritas subkriteria dengan menggunakan proses AHP. 


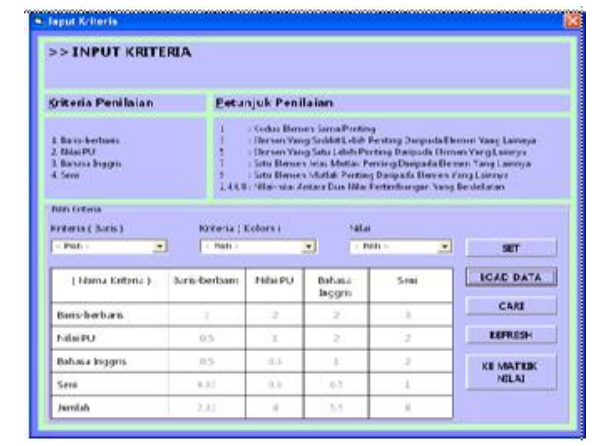

Gambar 3.3. Form Input Kriteria

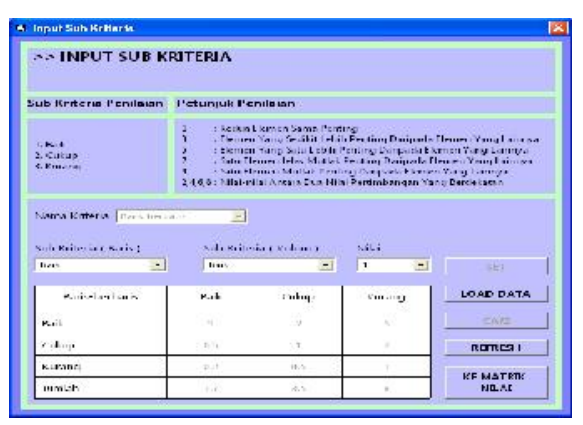

Gambar 3.4. Form Input Subkriteria

3. Menu Laporan

Menu laporan terdiri dari tiga sub menu laporan yaitu :

a. Sub menu laporan data calon peserta Menampilkan laporan data seluruh calon peserta Paskibraka tingkat Nasional di Dinas Pedidikan dan Olahraga Provinsi Sumatera Barat

b. Sub menu laporan keputusan seluruh calon siswa baru

Menampilkan laporan keputusan seluruh calon peserta Paskibaraka tingkat Nasional Provinsi Sumatera Barat

c. Sub menu laporan keputusan peserta yang lulus seleksi

Menampilkan laporan keputusan peserta yang lulus seleksi di Dinas
Pendidikan dan Olahraga Provinsi Sumatera Barat

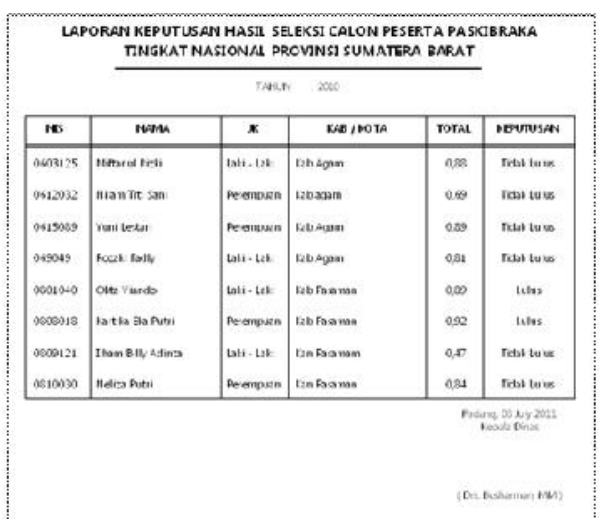

Gambar 3.5. Laporan Hasil Seleksi

\section{Kesimpulan dan Saran}

\subsection{Kesimpulan}

Sebagai penutup pembahasan dalam penulisan tugas akhir, penulis mengambil kesimpulan - kesimpulan sekaligus memberikan saran kepada pembaca yang menggunakan aplikasi dalam menyeleksi Anggota Paskibraka. Dengan adanya kesimpulan dan saran ini dapatlah diambil kesimpulan :

1. Pengolahan data untuk seleksi calon peserta Paskibraka tingkat Nasional belum memanfaatkan sistem komputer dan keputusan diambil secara manual hanya berdasarkan pertimbangan pengambil keputusan.

2. Keputusan untuk menentukan peserta Paskibraka tingkat Nasional yang diterima akan menentukan kinerja Dinas Pendidikan dan Olahraga selaku pihak yang ditunjuk sebagai penyeleksi untuk 
mendapatkan peserta Paskibraka yang berkualitas.

3. Metode yang digunakan pada sistem pendukung keputusan ini pada dasarnya adalah metode yang mengakumulasikan keputusan atas dasar pemenuhan berbagai kriteria tertentu. Kriteria penilaian dibuat kuantitatif untuk memudahkan perhitungan.

4. Sistem pendukung keputusan untuk seleksi calon peserta Paskibraka tingkat Nasional ini diharapkan dapat mendukung proses seleksi yang lebih berkualitas, transparan, cepat serta tersedianya basis data sumber daya manusia bagi Dinas Pendidikan dan Olahraga Provinsi Sumatera Barat.

\subsection{Saran}

Adapun saran yang dapat penulis berikat antara lain :

1. Diharuskan kepada pengguna aplikasi terlebih dahulu mengerti dasar - dasar penggunaan komputer.

2. Adanya penggantian sistem yang lama ke sistem yang baru dan diperlukan waktu untuk penyesuaian dalam melaksanakan perubahan yang terjadi pada sistem yang lama. Pergantian sistem dilakukan secara bertahap.

3. Aplikasi ini masih memiliki kelemahan, oleh karenanya disarankan bagi para pembaca agar dapat mengembangkannya, baik dari tampilan ataupun metodenya.

\section{DAFTAR PUSTAKA}

Asri, Renita. 2003, Decision Support Sistem

Dalam Trend Teknologi Bisnis dan Industri, Dalam Majalah Ilmiah UPIYPTK Vol.4 No. 1, (Maret), Padang

Kadarsah Suryadi M, Ali Ramdani, 2000, Sistem Penunjang Keputusan, PT Remaja Rosdakarya, Bandung.

Turban, E., Aronson, J.e., Liang, T., Sharda, R. 2007. : "Decission Support and Business Intelligence Systems". Eight Edition. Upper Saddle River, New Jersey: Pearson Pentice Hall.

Ibnu Syamsi, S.U, 1989, Pengambilan

Keputusan, PT Bina Aksara, Jakarta,

Kurniadi, Adi. 2003. "Pemrograman Microsoft

Visual Basic 6.0 “ Jakarta: PT.

Elexmedia Komputindo Kelompok

Gramedia.

Tim Penelitian dan Pengembangan

MADCOMS. 2003.Aplikasi Database \&

Crystal Report Pada Visual Basic 6.0.

Yogyakarta: Andi Offset. 